\title{
Role of Endothelium and Adventitia on Eugenol-Induced Relaxation of Rabbit Ear Artery Precontracted by Histamine
}

\author{
Hiroaki NishijImA ${ }^{1)}$, Ryuji Uchida ${ }^{2)}$, Nozomi KawaKAmi ${ }^{3)}$, Keiichi \\ SHImAmURA $^{4)}$ and Kenji KitAmURA ${ }^{3)}$ \\ ${ }^{1)}$ Department of Health and Sports Science, Kawasaki University of Medical \\ Welfare, Kurashiki, Okayama 701-0115, ${ }^{2}$ Departments of Oral Surgery, \\ ${ }^{3)}$ Pharmacology, Fukuoka Dental College, 2-15-1 Tamura, Sawara-ku, Fukuoka \\ 814-0193, and ${ }^{4}$ Research Institute of Hypertension, Kinki University, Osaka- \\ Sayama, Osaka 589-8511, Japan
}

\begin{abstract}
Eugenol $(\geq 0.1 \mathrm{mM})$ inhibited the contractions induced by various stimulants, such as 90 $\mathrm{mM}$ extracellular $\mathrm{K}^{+}$solution $\left(\left[\mathrm{K}^{+}\right]_{0}\right)$, histamine and noradrenaline in the rabbit ear artery. Inhibitory actions of eugenol occurred in a concentration-dependent manner, however, eugenol more dominantly inhibited the histamine-induced contraction than those induced by either $90 \mathrm{mM}\left[\mathrm{K}^{+}\right]_{0}$ solution or noradrenaline. Removal of both endothelium and adventitia did not change the inhibitory actions of eugenol on the $90 \mathrm{mM}\left[\mathrm{K}^{+}\right]_{0^{-}}$and noradrenalineinduced contractions, however, attenuated those on the histamine-induced contraction. Chlorphenylamine abolished the histamine-induced contraction, but neither cimetidine, ranitidine nor thioperamide modified the eugenol actions on the contractions induced by histamine. Pretreatment with nitric oxide syntheses inhibitor $\mathrm{N}^{\mathrm{G}}$-nitro-L-arginine (LNNA ; $100 \mu \mathrm{M}$ ), but not soluble guanylate cyclase inhibitor methylene blue (MB ; $10 \mu \mathrm{M}$ ), prevented endothelium/adventitia-dependent augmentation of the eugenol-induced relaxation on the histamine-induced contraction. When an intact tissue, but not an endothelium/ adventitia-denuded tissue, was placed at the up-stream close to the other denuded preparation (test preparation), histamine-induced contraction observed in the test preparation tended to be augmented. Similarly, eugenol-induced relaxation was also augmented by the same treatment.

Eugenol $(0.3 \mathrm{mM})$ inhibited the excitatory junction potentials (EJPs) without hyperpolarization of the membrane. However, a high concentration of eugenol (1 mM) slightly hyperpolarized the membrane (ca. $5 \mathrm{mV}$ ). No transient enhancement of amplitude of EJP was recorded.

These results suggest that eugenol may inhibit the histamine-induced muscle contraction directly, and the inhibition is augemented by the adventitia and endothelium partly by vasoactive substances, which were released from the adventitia/endothelium-derived substances in rabbit ear artery.
\end{abstract}

Correspondence to : Dr. K. Kitamura, Departments of Pharmacology, Fukuoka Dental College, 2-15-1 Tamura, Sawara-ku, Fukuoka 814-0193, Japan

Phone: +81-92-801-0411 Fax: +81-92-801-4909 e-mail : kenuran@college.fdcnet.ac.jp 
Key Words : eugenol, vascular cells, relaxation, adventitia, endothelium, EDRF, neurotransmission

\section{Introduction}

Eugenol, a pungent oil and a main ingredient of clove oil, is normally used for sedation of toothache and dental hyperalgesia in dental clinics. Although a main effect of eugenol is thought to be analgesic actions by inhibition of cyclooxygenase and lipoxygenase (Feng et al., 1987 ; Thompson et al., 1989 ; Dohi et al., 1991), vasodilating actions are also concomitantly observed by application of eugenol (Hume, 1983 ; Nishijima et al., 1998). In the previous paper (Nishijima et al., 1998), we found that eugenol inhibited the high extracellular $\mathrm{K}^{+}$solution (90 $\mathrm{mM}\left[\mathrm{K}^{+}\right]_{0}$ )-induced contraction of rabbit thoracic aorta without proportional change in the intracellular $\mathrm{Ca}^{2+}$ concentrations $\left(\left[\mathrm{Ca}^{2+}\right]_{\mathrm{i}}\right)$. However, as we used the both endothelium- and adventitia-denuded preparation, influences of either endothelium or adventitia on the eugenolinduced relaxation has not yet investigated.

It is clinically and pharmacologically important to know contribution of endothelial cells, neurons or other perivascular cells in the vasodilating mechanisms of eugenol for evaluation of the actions of this agent in in vivo and in vitro, in which endothelium and adventitia are intact (Hume 1983 ; Shibata et al., 1994). Because, eugenol is also known to release substance P and calcitonin-gene related peptide (CGRP) from the peripheral nerve ending, spinal chord and dental pulp (Bevan et al., 1990 ; Shibata et al., 1994), possibly through activation of capsaicin receptor and non-selective cation channels in the perivascular neurons and other cells (Patacchini et al., 1990 ; Ohkubo et al., 1997a ; Ohkubo et al., 1997b). However, contributions of the endothelium and perivascular tissue on the vasodilating actions of eugenol have not yet known.

The present experiments were designed to elucidate roles of the adventitia and endothelium on the eugenol-induced vasorelaxation of the central ear artery of rabbit using isometric tension and membrane potential recordings.

\section{Materials}

Male rabbits (Nippon White $1.5-1.7 \mathrm{~kg}$ ) were anesthetized by pentobarbital $(40 \mathrm{mg} / \mathrm{kg}$ i.v.) and exanguinated. Central ear artery was carefully isolated with fine scissors. For tension and membrane potential recordings, small pieces of ear artery $(0.5 \mathrm{~mm}$ in diameter, $0.5-0.7 \mathrm{~mm}$ in length for isometric tension recording and $10 \mathrm{~mm}$ in length for microelectrode experiments) were mounted in the organ bath. The modified Krebs solution $\left(32-35^{\circ} \mathrm{C}\right)$ was superfused with the flow rate of $2 \mathrm{ml} / \mathrm{min}$.

\section{Isometric tension recording}

The ring preparations of rabbit ear artery were horizontally mounted in a small organ bath ( $0.5 \mathrm{ml}$ in volume) with pair of thin wires (100 $\mu \mathrm{m}$ in diameter). One of these wires was fixed on the wall of the organ bath and the other tied to the force displacement transducer (TB$651 \mathrm{~T}$; Nihon Kohden, Tokyo). Finally, isometric tension was recorded with a conventional 
ink-writing pen recorder (R-62 ; Rika Denki Kogyo, Tokyo) through a carrier amplifier (EF$601 \mathrm{G}$; Nihon Kohden). Each preparation was equilibrated with a warmed Krebs solution $\left(35^{\circ} \mathrm{C}\right)$ for $30-60 \mathrm{~min}$. In some experiments, adventitia and/or endothelium-denuded tissues were prepared by dissecting the surrounded connective tissue by fine scissors and/or scrubbing the inner vessel wall with fine cotton threads. To confirm the removal of endothelium, acetylcholine and substance $\mathrm{P}$ were applied, and preparations, produced no response by acetylcholine or substance $\mathrm{P}$, were used in the present experiments.

\section{Membrane Potential Recording}

The ring preparation of the rabbit ear artery was fixed onto a rubber plate with fine pins. The membrane potential was measured following impalement with a fine glass microelectrode (30-50 M $\Omega$; filled with $3 \mathrm{M} \mathrm{KCl)} \mathrm{from} \mathrm{the} \mathrm{adventitia} \mathrm{side} \mathrm{using} \mathrm{a} \mathrm{micromanipulator} \mathrm{(MP-1} \mathrm{;}$ Narishige Sci. Instrum. Lab., Tokyo). The membrane potential was monitored with an oscilloscope and thermo-writing pen recorder (VC-10; Nihon Kohden, Hioki 8804 Memory Hicorder; Hioki, Tokyo) through a pre-amplifier (MEZ-8301; Nihon Kohden). In some experiments, electrical stimulation with short train pulses (0.1 ms in duration; $3-5$ pulses) was applied through $\mathrm{Ag}-\mathrm{AgCl}$ electrode which was placed on the tissue near the microelectrode $(<0.3 \mathrm{~mm})$. In all microelectrode experiments, we use the endothelium- and adventitia-intact preparations.

\section{Solution and drugs}

The modified Krebs solution was used in the present experiments with following composition (mM) : $\mathrm{NaCl} 121.9, \mathrm{KCl} 4.7, \mathrm{MgCl}_{2}$ 1.2, $\mathrm{CaCl}_{2} 2.5, \mathrm{NaHCO}_{3} 15.5, \mathrm{KH}_{2} \mathrm{PO}_{4} 1.2$ and glucose 11.5. The $\mathrm{pH}$ of the solution was kept at 7.3-7.4 with $5 \% \mathrm{CO}_{2}-95 \% \mathrm{O}_{2}$. Drugs used in the present experiments were noradrenaline, histamine, cimetidine, chlorophenylamine, ranitidine, thioperamide, methylene blue (BM) $\mathrm{N}^{\mathrm{G}}$-nitro-L-arginine (LNNA) (all from Sigma Chem., St. Louis, MO, USA) and eugenol (Tokyo Kasei, Tokyo). Eugenol was dissolved in dimethyl sulfoxide (DMSO; Sigma Chem). The final concentration of DMSO was kept at less than $0.1 \%$, and this concentration of DMSO was confirmed to have no effect on either the tension and membrane potential.

\section{Statistics}

The results were expressed as mean \pm S.D.. Statistical significance was assessed with Student's t-test and $\mathrm{P}$ value less than 0.05 was considered to be significant.

\section{Results}

Specificity of vasodilation by phenol derivatives on the contractions induced by histamine

In rabbit ear artery, histamine $(1 \mu \mathrm{M})$ evoked a phasic followed by a sustained contraction (Fig. 1). This histamine-induced contractions could be recorded repeatedly, when histamine was applied with interval of longer than $15 \mathrm{~min}$. Application of eugenol $(1 \mathrm{mM})$ markedly inhibited the histamine-induced contraction. On the other hand, the same concentration of 
A

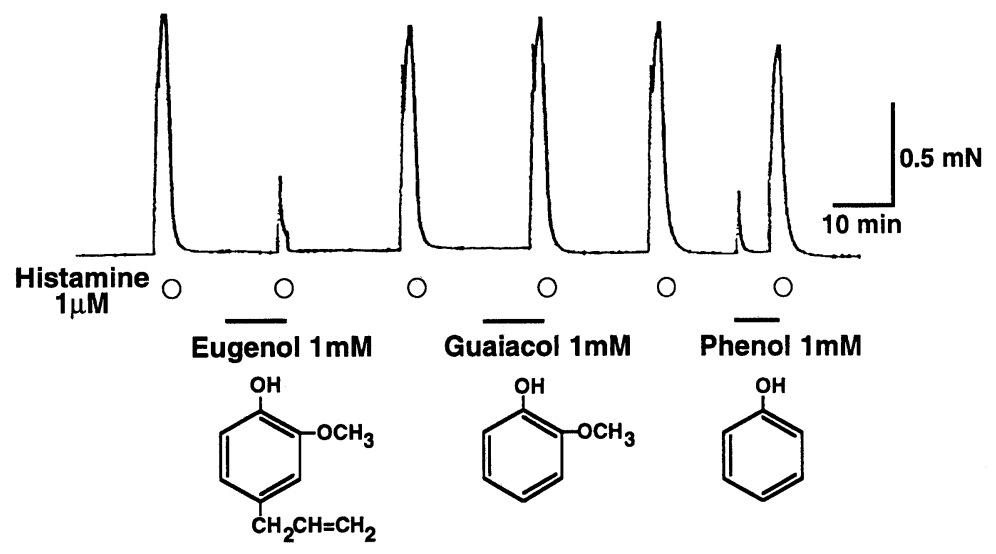

B

a

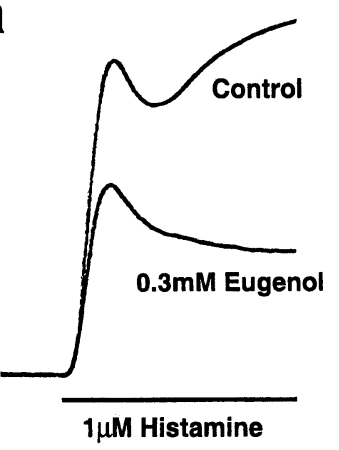

b

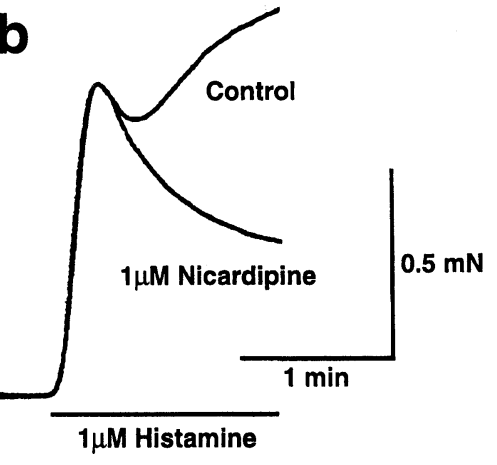

Fig. 1. Effects of eugenol, guaiacol and phenol on the histamine-induced contractions in the rabbit ear artery and their chemical structures (A), and effects of eugenol and nicardipine on the histamine-induced contractions with fast time scale (B). (A) Histamine $(1 \mu \mathrm{M})$ was applied every $20 \mathrm{~min}$ at the time indicated by open circles ( $2 \mathrm{~min}$ in duration). Eugenol (1 $\mathrm{mM})$, guaiacol $(1 \mathrm{mM})$ and phenol $(1 \mathrm{mM})$ were applied for $7-10 \mathrm{~min}$ prior to application of histamine. (B) Traces of the histamine-induced contractions obtained in the presence and absence of $0.3 \mathrm{mM}$ eugenol (a) or $1 \mu \mathrm{M}$ nicardipine (b) were superimposed.

guaiacol and phenol, which had similar chemical structures, did not inhibit significantly the histamine-induced contraction (Fig. 1A). As shown in Fig. 1Ba, eugenol-induced inhibition was more dominantly observed on the sustained contraction (tonic component) than the phasic contraction of the histamine-induced contraction. Nicardipine $(1 \mu \mathrm{M})$ did suppress the tonic, but not phasic component of the contractions (Fig. 1Bb). As, in many preparations, it was difficult to separate the phasic component from the tonic component (see Figs. 3 and 5A), we investigated the actions of eugenol on the tonic component of the contraction.

Effects of eugenol on the contractions induced by histamine, noradrenaline and $90 \mathrm{mM}[\mathrm{K}]_{0}$ in adventitia-intact and denuded preparations

Fig. 2 shows inhibitory actions of eugenol on the $90 \mathrm{mM}\left[\mathrm{K}^{+}\right]_{0^{-}}, 1 \mu \mathrm{M}$ histamine- and $1 \mu \mathrm{M}$ 
noradrenaline-induced contractions. These stimulations produced similar amplitudes of contraction in the rabbit ear artery (Fig. 2A). Eugenol (0.03-3 mM) inhibited these contractions in a concentration-dependent manner (Fig. 2B). Extent of the inhibition of the amplitudes did not differ significantly between noradrenaline- and $90 \mathrm{mM}\left[\mathrm{K}^{+}\right]_{0}$-induced contractions, however, this vasorelaxing effects of eugenol $(0.1-1 \mathrm{mM})$ were dominantly seen on the histamine-induced contraction.

To study the influence of adventitia and endothelium on the histamine-, noradrenaline- and $90 \mathrm{mM}\left[\mathrm{K}^{+}\right]_{0}$-induced contractions, effects of eugenol were investigated on either the adventitia or endothelium-denuded preparations. Fig. 3 shows typical traces of the eugenol actions on the $1 \mu \mathrm{M}$ histamine-induced contraction. To confirm whether endothelium was removed or not, $1 \mu \mathrm{M}$ acetylcholine was applied on either the noradrenaline- or $90 \mathrm{mM}\left[\mathrm{K}^{+}\right]_{0}$-induced contraction. As shown in Fig. 3A, acetylcholine relaxed the noradrenaline-induced contraction in the endothelium-intact preparation (Fig. 3Aa), but not in the endothelium-denuded preparation (Fig. 3Ab). Histamine $(1 \mu \mathrm{M})$ contracted the same preparations with slightly smaller amplitudes than those by noradrenaline-induced contractions in this preparations. Application of $1 \mathrm{mM}$ eugenol inhibited the contractions induced by $1 \mu \mathrm{M}$ histamine in both preparations, but larger inhibition was observed in the endothelium-intact preparation than denuded one (Fig. 3B). Similarly, larger inhibition was also observed in the adventitia-intact preparation than denuded one by application of 0.3 and $1 \mathrm{mM}$ eugenol (Fig. 3C).

A

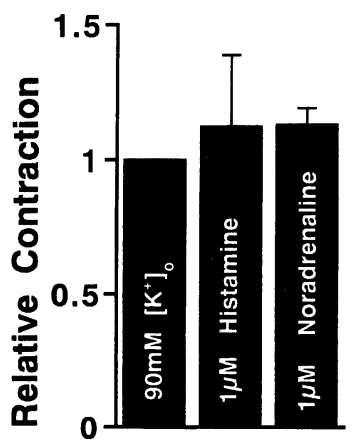

B

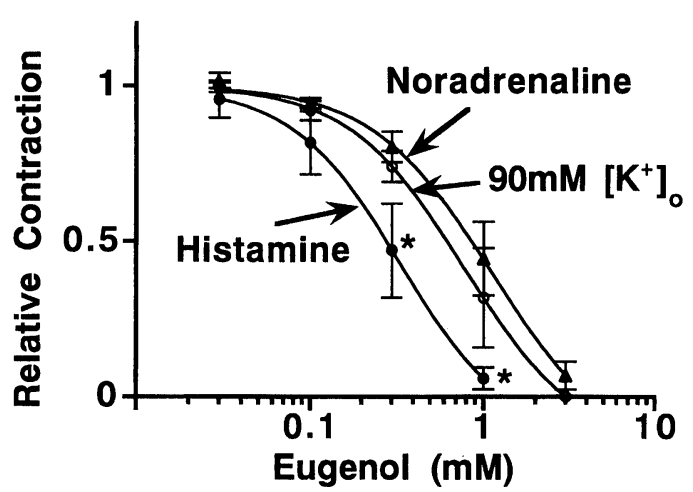

Fig. 2. Relative amplitude among $90 \mathrm{mM}\left[\mathrm{K}^{+}\right]_{0}$ solution, $1 \mu \mathrm{M}$ histamine- and $1 \mu \mathrm{M}$ noradrenaline-induced contraction (A) and concentration inhibition curves of eugenol (B). (A) The amplitude of the $90 \mathrm{mM}\left[\mathrm{K}^{+}\right]_{0}$-induced was normalized as 1.0 , and those of histamine and noradrenaline were expressed as relative values. Each data represent the mean $\pm \mathrm{SD}$ of 6 samples. (B) Effects of eugenol on the $90 \mathrm{mM}\left[\mathrm{K}^{+}\right]_{0^{-}}, 1 \mu \mathrm{M}$ noradrenaline- and $1 \mu \mathrm{M}$ histamine-induced contractions. The amplitudes of each contraction in the absence of eugenol were normalized as 1.0, respectively, and those in the presence of eugenol were expressed in a relative manner. Amplitudes of $90 \mathrm{mM}\left[\mathrm{K}^{+}\right]_{0^{-}}$(open circles), $1 \mu \mathrm{M}$ histamine- (closed circles) and $1 \mu \mathrm{M}$ noradrenaline- (triangles) induced contractions were measured just before removal of stimulant (tonic component). ${ }^{*}$ indicates $p \leq 0.05$ (Histamine vs. $90 \mathrm{mM}\left[\mathrm{K}^{+}\right]_{0}$ and Noradrenaline). Each data points represent the mean $\pm \mathrm{SD}$ of 6 samples. 


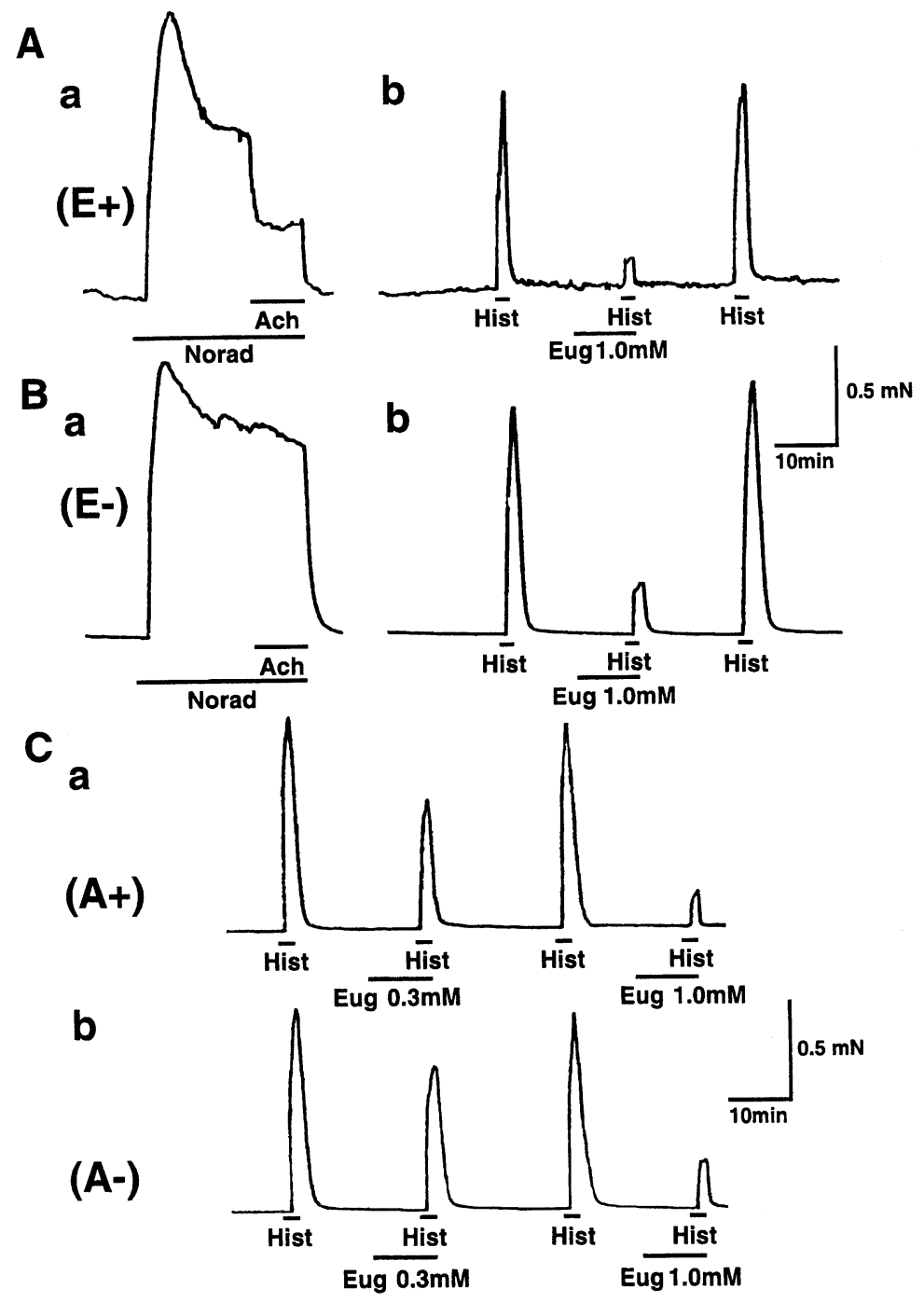

Fig. 3. Effects of eugenol on the histamine-induced contraction recorded in the preparations of rabbit ear artery in the presence or absence of either endothelium or adventitia. (A), (B) Effects of eugenol on the endothelium-intact $(\mathrm{E}+)$ and denuded $(\mathrm{E}-)$ preparations. Noradrenaline (Norad, $1 \mu \mathrm{M}$ ), acetylcholine (Ach, $1 \mu \mathrm{M})$, histamine (Hist, $1 \mu \mathrm{M}$ ) and eugenol (Eug, $1 \mathrm{mM}$ ) were applied at time indicated by bar. (C) Effects of eugenol on the adventitia-intact $(\mathrm{A}+)$ and denuded $(\mathrm{A}-)$ preparations. In this experiments, endothelium was also removed. Histamine (Hist ; $1 \mu \mathrm{M}$ ) and eugenol (Eug, 0.3 and $1 \mathrm{mM}$ ) were applied at time indicated by bar.

Fig. 4 summarizes the effects of various concentrations of eugenol on the $90 \mathrm{mM}\left[\mathrm{K}^{+}\right]_{0^{-}}$, $1 \mu \mathrm{M}$ noradrenaline- and $1 \mu \mathrm{M}$ histamine-induced contractions in adventitia- and/or endothelium-intact or denuded preparations. Inhibitory actions of eugenol, on the $90 \mathrm{mM}\left[\mathrm{K}^{+}\right]_{0}-$ and noradrenaline-induced contractions, were not affected by removal of endothelium and adventitia (Fig. 4A and 4B). On the other hand, relaxation by eugenol ( 0.3 and $1 \mathrm{mM})$ on the histamine-induced contraction was significantly attenuated in the adventitia/endothelium- 


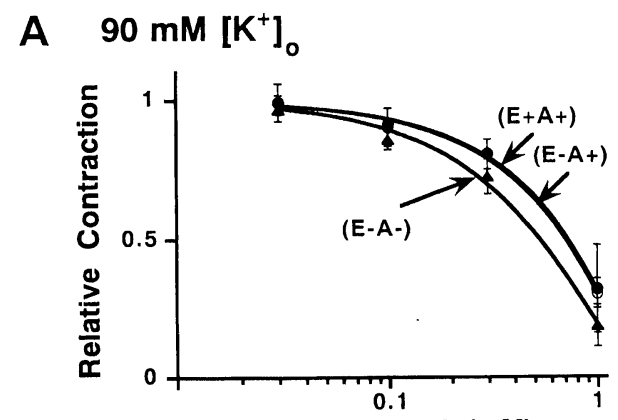

B Noradrenaline Eugenol (mM)

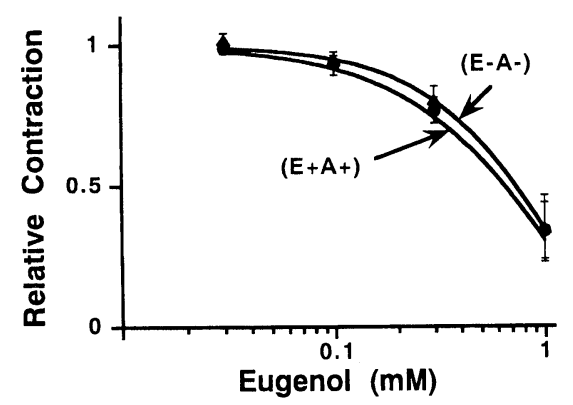

C Histamine

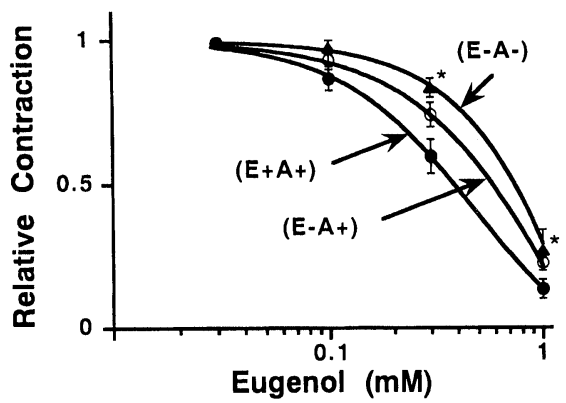

Fig. 4. Concentration-inhibition curves of eugenol in rabbit ear arteries precontracted $90 \mathrm{mM}$ $\left[\mathrm{K}^{+}\right]_{0^{-}}(\mathrm{A}), 1 \mu \mathrm{M}$ noradrenaline- (B) and $1 \mu \mathrm{M}$ histamine- $(\mathrm{C})$. The amplitudes in the absence of eugenol were normalized as 1.0, respectively. Amplitudes were measured just before removal of stimulant (tonic component). (A) (C) Responses were recorded from the endothelium/adventitia-intact ( $\mathrm{E}+\mathrm{A}+$; closed circles), endothelium-denuded but adventitia-intact (E-A+; open circles) and endothelium/adventitia-denuded (E-A-; triangles) preparations. (B) Responses were recorded from the endothelium/adventitiaintact $(\mathrm{E}+\mathrm{A}-$; closed circles) and endothelium/adventitia-denuded (E-A - ; triangles) preparations. ${ }^{*}$ indicates $p \leq 0.05\{(\mathrm{E}+\mathrm{A}+)$ vs. $(\mathrm{E}-\mathrm{A}-)\}$. Data points of each preparation in figures represent the mean $\pm \mathrm{SD}$ of 6 samples.

denuded preparation (Fig. 4C). These results indicated that endothelium and/or adventitia may contribute to produce larger inhibition by eugenol in the histamine-induced contraction.

To confirm contribution of adventitia in the histamine-induced contraction and its inhibition by eugenol, we recorded the histamine-induced contractions from the endothelium/ adventitia-denuded preparation (test preparation) in the presence of either adventitia-intact or denuded preparation (conditioning preparation), which was placed close to the test preparation 
from the up-stream of the organ bath. For this purpose, we used endothelium-denuded conditioning preparations. Fig. 5A is an example of such experiments. As shown in Fig. 5Aa, acetylcholine $(1 \mu \mathrm{M})$ did not relax the contractions induced by $90 \mathrm{mM}\left[\mathrm{K}^{+}\right]_{0}$, suggesting
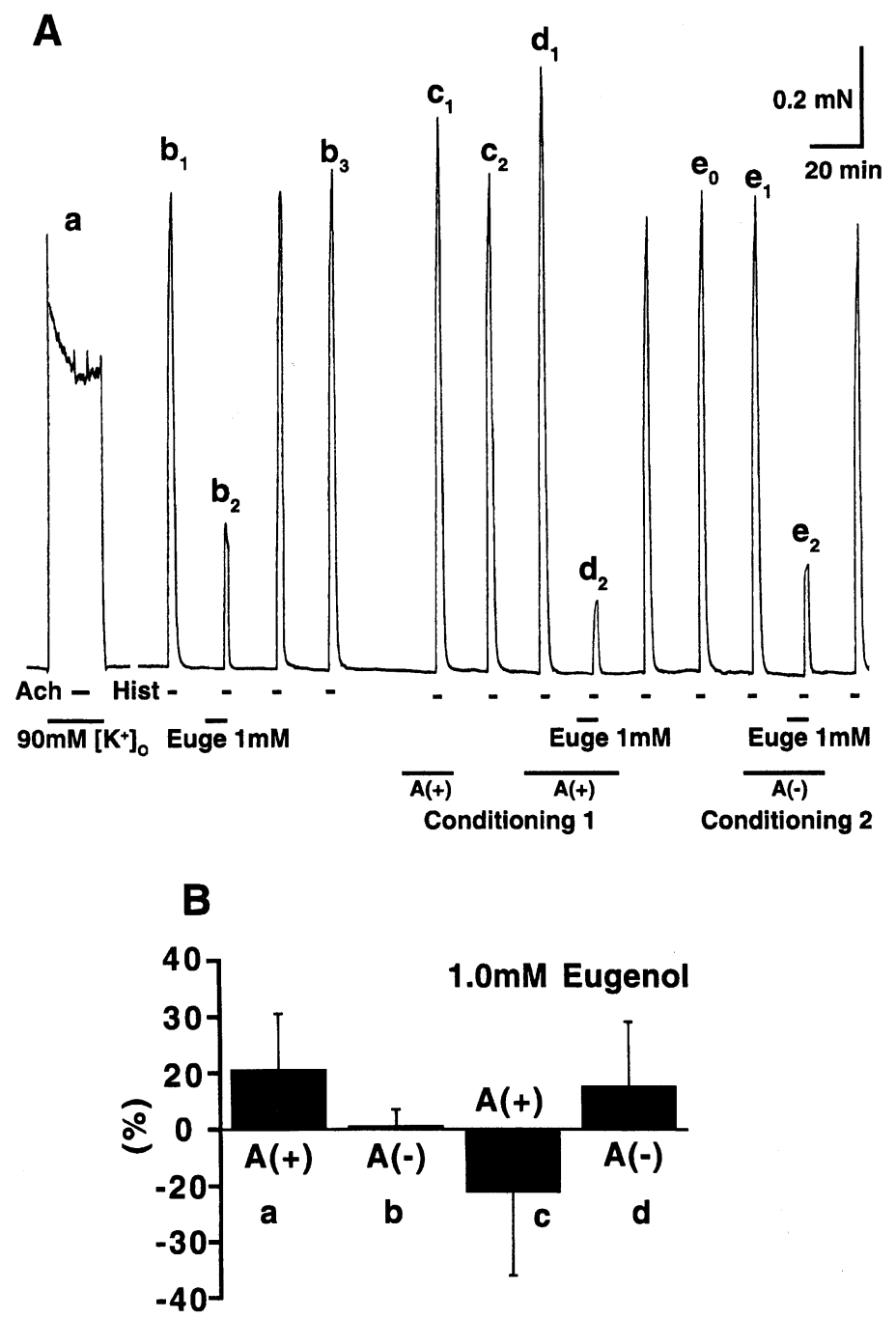

Fig. 5. Effects of eugenol on the histamine-induced contractions recorded from the endothelium/ adventitia-denuded preparation. (A) $90 \mathrm{mM}\left[\mathrm{K}^{+}\right]_{0}$ solution, acetylcholine (Ach ; $1 \mu \mathrm{M}$ ), histamine (Hist, $1 \mu \mathrm{M}$ ) and eugenol (Eug, $1 \mathrm{mM}$ ) were applied at the time indicated by bar. In (a) and (b), an endothelium/adventitia-denuded preparation (test preparation) is present alone in the organ bath. In (c) and (d), a second preparation (adventia-intact preparation$\mathrm{A}+)$ was placed close to the test preparation. $=($ Conditioning 1$)$ In $(\mathrm{e})$, an another second preparation (adventia-denuded preparation- $\mathrm{A}-$ ) was placed close to the test preparation. $=($ Conditioning 2) $\quad$ (B) Summary of influences of the histamine-induced contraction and its eugenol-induced inhibition obtained from 6 experiments in A. The amplitudes of the contractions were measured just before removal of eugenol (tonic component). The amplitude of the $1 \mu \mathrm{M}$ histamine-induced contraction was normalized as $1.0(\mathrm{a}$ and $\mathrm{b})$ and that in the presence of $1 \mathrm{mM}$ eugenol as 1.0 (c and $\mathrm{d}$ ). $\mathrm{A}(+)$ and $\mathrm{A}(-)$ shows a second preparation (adventia-intact and denuded preparation). Data points of each preparation in figures represents the mean $\pm \mathrm{SD}$ of 6 samples. 
endothelium of this preparation was completely removed. In the absence of the conditioning preparation, the test preparation was contracted by application of $1 \mu \mathrm{M}$ histamine (Fig. $5 \mathrm{Ab}_{1}$ ). Pretreatment with eugenol $(1 \mathrm{mM})$ attenuated the histamine-induced contraction (Fig. $\left.5 \mathrm{Ab}_{2}\right)$, and removal of eugenol restored the amplitude of the histamine-induced contraction (Fig. $\left.5 \mathrm{Ab}_{3}\right)$. When an adventitia-intact preparation was placed at up-stream close to the test preparation, histamine-induced contraction was augmented (Fig. $5 \mathrm{Ac}_{1}$ and $\mathrm{d}_{1}$, Conditioning 1). This augmentation of the histamine-induced contraction ceased when conditioning preparation was moved away from the test preparation (Fig. $5 \mathrm{Ac}_{2}$, second contraction). In this condition (with close placing the adventitia-intact conditioning preparation), eugenol (1 mM) produced larger inhibition of the histamine-induced contraction than that observed in the absence of the conditioning preparation (Fig. $5 \mathrm{Ab}_{2}$ vs. Fig. $5 \mathrm{Ad}_{2}$ ). On the other hand, when the adventitiadenuded preparation was placed to the same position, no augmentation was observed by histamine (Fig. $5 \mathrm{Ae}_{0}$ vs. Fig. $5 \mathrm{Ae}_{1}$, Conditioning 2) and inhibitory effects of $1 \mathrm{mM}$ eugenol were also attenuated (Fig. $5 \mathrm{Ae}_{2}$ ). Fig. 5B is a summary of these experiments. In the presence of the adventitia-intact preparation, amplitude of the histamine-induced contraction was increased to $1.21 \pm 0.20(n=6)$ (Fig. $5 \mathrm{Ba})$, whereas in the presence of the adventitia-denuded preparation, the amplitude was not change $(1.01 \pm 0.06 ; n=6 ; \mathrm{p}<0.05$; Fig. $5 \mathrm{Bb}$, Conditioning 2$)$, suggesting a possible release of some vasoactive substances from adventitia by histamine. In the absence of the conditioning preparation, eugenol $(1 \mathrm{mM})$ inhibited the histamine-induced contraction to $0.23 \pm 0.08(n=6)$ of the control (in the absence of eugenol). In the presence of the adventitiaintact preparation, eugenol $(1 \mathrm{mM})$ produced a larger inhibition $(0.14 \pm 0.04 ; n=6$, Conditioning 1 ), however, in the presence of the adventitia-denuded preparation, the same concentration of eugenol produced a smaller inhibition $(0.26 \pm 0.06 ; n=6$, Conditioning 2$)$. When the histamineinduced contractions of the test preparation in the presence of eugenol without the conditioning preparation was normalized as 1.0, the amplitudes of those in the presence of either conditioning preparation were $0.78 \pm 0.3(n=6)$ in the presence of the adventitia-intact preparation (Fig. $5 \mathrm{Bc}$, Conditioning 1$)$ and $1.15 \pm 0.23(n=6)$ in the presence of the adventitia-denuded preparation (Fig. 5Bd, Conditioning 2). When an endothelium/adventitia-intact tissue pretreated by heat $\left(60^{\circ} \mathrm{C}\right.$ for $\left.45 \mathrm{~min}\right)$ was used as a conditioning preparation, augmentation was observed neither on the histamine-induced contraction nor eugenol-induced relaxation (data not shown).

\section{Pharmacological characteristics of the histamine-induced contraction}

Application of cimetidine $(1$ and $10 \mu \mathrm{M})$, ranitidine $(1$ and $10 \mu \mathrm{M})$ or thioperamide $(1 \mu \mathrm{M})$ had no effect on the inhibitory actions of eugenol in the endothelium/adventitia-intact preparations, while chlorophenylamine $(1 \mu \mathrm{M})$ completely inhibited the histamine-induced contraction (data not shown). Furthermore, when endothelium/adventitia-intact tissue, but pretreated either cimetidine $(10 \mu \mathrm{M})$ or thioperamide $(1 \mu \mathrm{M})$, was used as a conditioning preparation, augmentation was observed both on the histamine-induced contraction and eugenol-induced relaxation, suggesting no contribution of the $\mathrm{H}_{2}$ - and $\mathrm{H}_{3}$-receptor on the histamine-induced contraction (data not shown). 
Effects of LNNA and methylene blue on the eugenol-induced relaxation

To elucidate a candidate for vasodilator substances released from perivascular neurons or cells, $100 \mu \mathrm{M}$ LNNA was applied to the tissue, and histamine and eugenol were applied. Fig. 6 shows that the effects of LNNA and methylene blue on the eugenol-induced relaxation. Inhibitory actions of eugenol on the endothelium/adventitia-intact preparation were significantly attenuated by $100 \mu \mathrm{M}$ LNNA, at the concentrations of 0.3 and $1 \mathrm{mM}$ (Fig. 6A).
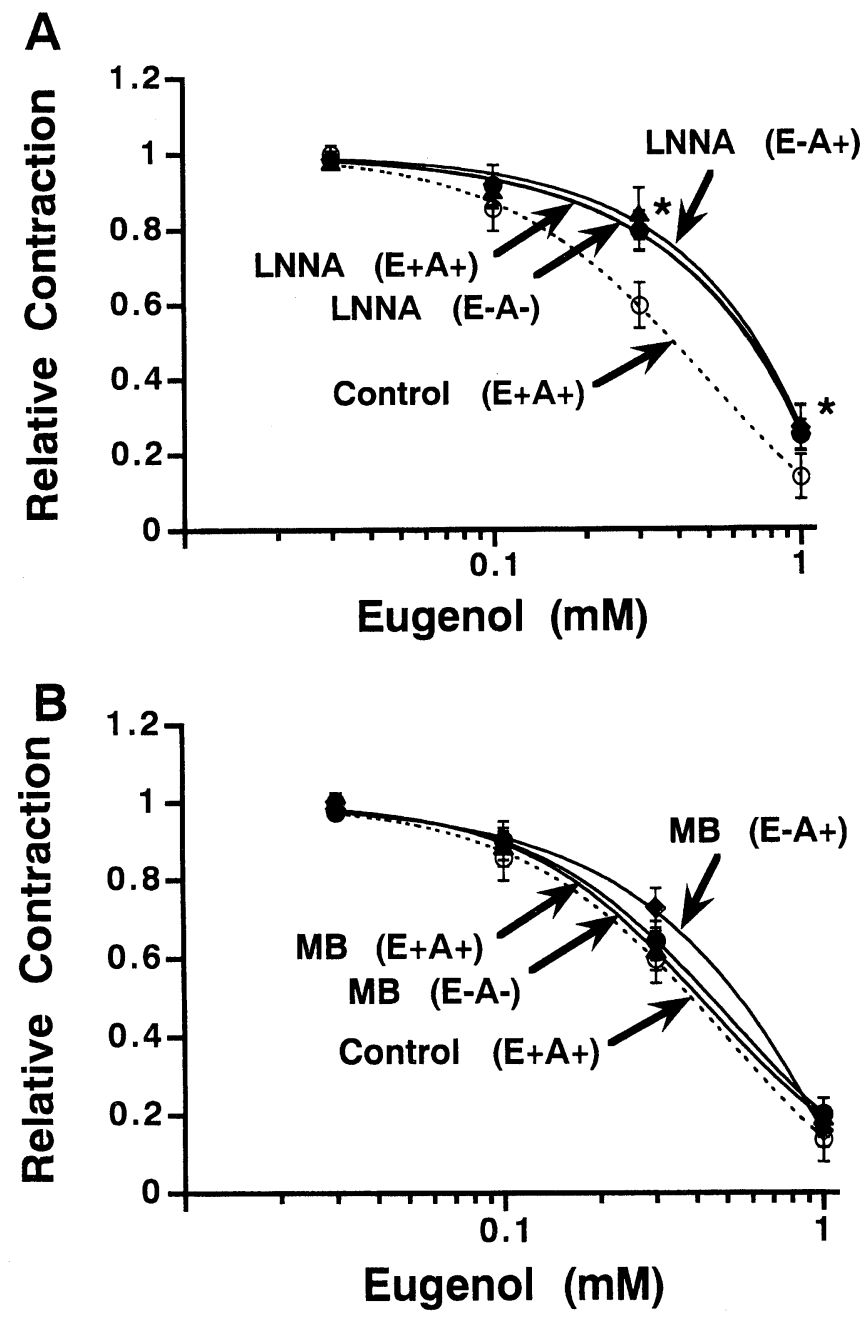

Fig. 6. Effects of $\mathrm{N}^{\mathrm{G}}$-nitro-L-arginine (LNNA) (A) and methylene blue (MB) (B) on the concentration-inhibition courves of eugenol in the endothelium/adventitia-intact and denuded preparations precontracted with $1 \mu \mathrm{M}$ histamine. The amplitudes in the absence of eugenol were normalized as 1.0. Amplitudes were measured just before removal of stimulant (tonic component). (A) Effects of $100 \mu \mathrm{M}$ LNNA. (B) Effects of $10 \mu \mathrm{M}$ methylene blue. Responses were recorded from the endothelium/adventitia-intact (E+ $\mathrm{A}+$ ), endothelium-denuded but adventitia-intact $(\mathrm{E}-\mathrm{A}+)$ and endothelium/adventitiadenuded $(\mathrm{E}-\mathrm{A}-)$ preparations. $*$ indicates $p<0.05\{$ Control $(\mathrm{E}+\mathrm{A}+)$ vs. LNNA $(\mathrm{E}+$ $\mathrm{A}+$ ), LNNA $(\mathrm{E}-\mathrm{A}+)$ and LNNA $(\mathrm{E}-\mathrm{A}-)\}$. Data points of each preparation in figures represents the mean $\pm \mathrm{SD}$ of 6 samples. 
However, LNNA did not further attenuated eugenol-induced inhibition recorded in the endothelium/adventitia-denuded and endothelium-denuded but adventitia-intact preparations (Fig. 6A). Application of $10 \mu \mathrm{M}$ methylene blue, an inhibitor of soluble guanylate cyclase, did not attenuated the inhibitory actions of eugenol in any type of the preparations (Fig. 6B).

Application of $10 \mu \mathrm{M}$ indomethacin did not influenced on the amplitudes of histamineinduced contraction and its eugenol-induced inhibition (data not shown).

Effects of eugenol on the resting membrane potential and excitatory junction potential

The resting membrane potential of the smooth muscle cells of rabbit ear artery was $-57.6 \pm 4.9 \mathrm{mV}(n=15)$. Eugenol $(\leq 0.3 \mathrm{mM})$ did not change the resting membrane potential $(-59.3 \pm 7.7 \mathrm{mV} ; n=8$; Fig. 7A, upper trace), while $1 \mathrm{mM}$ eugenol hyperpolarized the membrane to $-61.5 \pm 3.7 \mathrm{mV}(n=7 ; p<0.05$; Fig. $7 \mathrm{~A}$, lower trace). Short train pulses $(0.1 \mathrm{~ms}$ in duration, $10 \mathrm{~Hz}, 3$ pulses) evoked excitatory junction potentials (EJPs) which were blocked by $0.1 \mu \mathrm{M}$ tetrodotoxin (data not shown). Application of $0.3 \mathrm{mM}$ eugenol inhibited the EJP without change in the resting membrane potential, whereas application of $1 \mathrm{mM}$ eugenol did with slightly hyperpolarization of the membrane (Fig. 7B). In both concentrations, eugenol did not produce any transient augmentation of EJP.

A

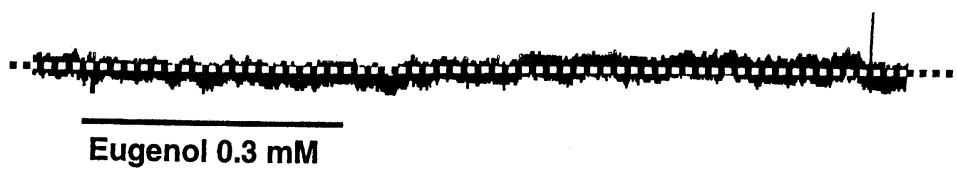

Eugenol $0.3 \mathrm{mM}$
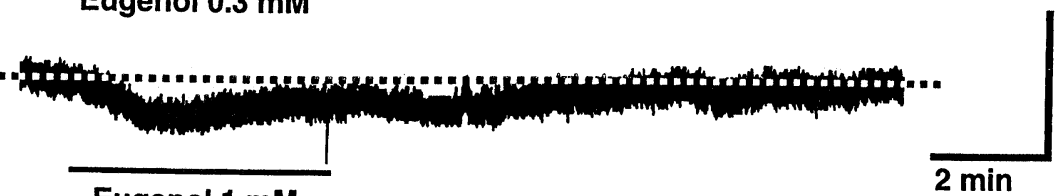

$20 \mathrm{mV}$

B

Eugenol $1 \mathrm{mM}$ $2 \min$
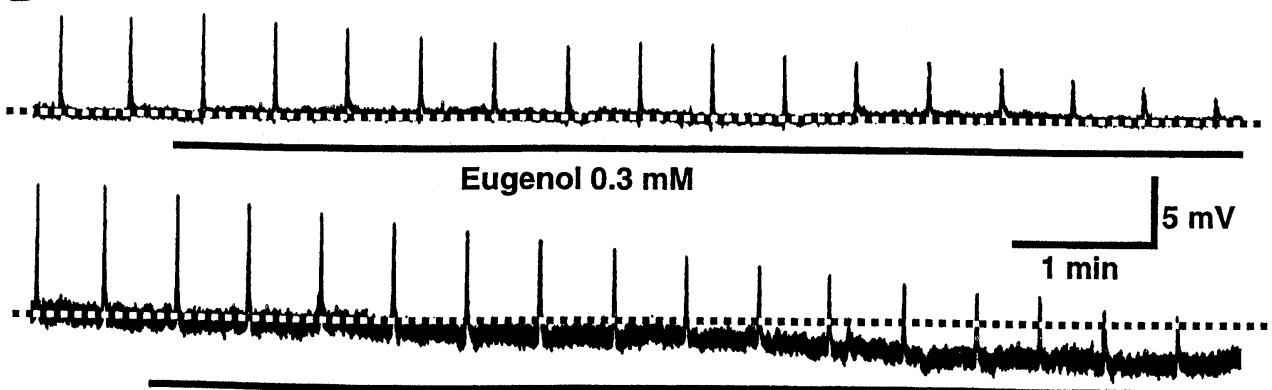

\section{Eugenol $1 \mathrm{mM}$}

Fig. 7. Effects of eugenol on the membrane potential (A) and the excitatory junctional potential (EJP) evoked by a transmural electrical stimulation (B). Eugenol (0.3 or $1 \mathrm{mM})$ was applied at the time indicated by bar. Dotted lines indicate the resting membrane potential before application of eugenol. In (B), transmural electrical stimulations $(0.1 \mathrm{~ms} ; 3-5$ pulses with $10 \mathrm{~Hz} ; 50 \mathrm{~V}$ ) were applied every $30 \mathrm{~s}$. Each trace was obtained from different preparations. 


\section{Discussions}

In the present experiments, we observed that eugenol dominantly inhibited the histamineinduced contraction in comparison to the noradrenaline- and $90 \mathrm{mM}\left[\mathrm{K}^{+}\right]_{0}$-induced contractions (Fig. 2B). This dominant inhibition of the histamine-induced contraction by eugenol was depended upon adventitia and endothelium (Fig. 3). If we assume that the endothelium/ adventitia-dependent augmentation of the eugenol actions was caused by the release of the vasoactive substance(s) from the endothelium/adventitia by this agent, the augmentation of the eugenol-induced inhibition should be observed in both noradrenaline- and $90 \mathrm{mM}\left[\mathrm{K}^{+}\right]_{0}$-induced contractions (Fig. 4A, B). Our results, in the present experiments, are contradictory to this assumption. Furthermore, we could record no augmentation, but inhibition of the EJP by application of 0.3 or $1 \mathrm{mM}$ eugenol in the rabbit ear artery (Fig. 7). Similarly, in phrenic nervediaphragm preparation, eugenol was reported to inhibit the end-plate potential at $0.65 \mathrm{mM}$ (Brodin et al., 1984). These evidences indicate that eugenol itself does not release the vasoactive substance(s) from endothelium and perivascular neurons and cells in the rabbit ear artery. Lack of the excitatory effects on the transmitter release from the nerve endings by eugenol might be a specific phenomenon in the ear artery, because same concentrations of eugenol, used in the present experiments, transiently augmented the histamine-induced contraction in the rabbit basilar artery (K. Kitamura, unpublished observations).

In this experiment, the dominant inhibition of the histamine-induced contraction by eugenol was seen in the adventitia and endothelium-denuded preparation (Fig. 4C). This inhibition of histamine-induced contraction by eugenol was a direct action to the smooth muscle cells. Concerning this direct action, Nishijima et al. (1998) discussed on the pharmacological properties of eugenol with several metabolic inhibitors, and speculated the metabolic inhibition might contribute to the eugenol-induced vasodilation in the adventitia and endothelium-denuded aorta. Thus, we speculated the involvements of both direct and indirect modulation of contractile machinery in its mechanisms.

Histamine has been shown to produce the endothelium-dependent relaxation in the artery, possibly releasing endothelium-derived relaxing substances, such as NO and prostanoids (Kuriyama et al., 1995). It has been also reported that histamine enhanced the contractions induced by transmural electrical stimulation in goat cerebral artery (Miranda et al., 1992). In the experiments shown in Fig. 5 of the present experiments, histamine certainly enhances the contraction possibly by a release of the vasoactive substance(s) from the adventitia. Although we did not test the identification of putative vasoactive substances on the adventitia-dependent augmentation, we could exclude a possible contribution of adenosine-triphosphate (ATP), as eugenol did not enhance the amplitudes of the EJPs. Miranda et al. (1992) reported that histamine released adrenaline from the perivascular nerves through activation of $\mathrm{H}_{1}$ receptor in the goat cerebral artery. If these are true, it is peculiar that why only adrenaline could be released by histamine, as both noradrenaline and ATP were co-exist in the same nerve endings as a co-transmitter. The decrease in EJP amplitude by eugenol may alternatively explained by depression of the ATP-induced response at the post-membrane. In addition to the histamine-induced release of the vasoconstricting substance(s), such as adrenaline, our results 
suggested that histamine also release the vasorelaxing substance(s) from the adventitia. In the present experiments, LNNA $(100 \mu \mathrm{M})$ did not significantly augment the histamine-induced contraction, but we found that LNNA prevented the eugenol-induced inhibition to the contraction (Fig. 6A). A possibility would be excluded that eugenol released NO from adventitia, as LNNA did not affect the eugenol-induced inhibition on the noradrenaline-induced contraction (K. Kitamura, unpublished observations). In the present experiments, we found that metylene blue, an inhibitor of soluble guanylate cyclase did not attenuated the inhibitory actions of eugenol as shown in Fig 6B. This results suggest that the inhibitory actions of eugenol observed in this experiments dose not relate to a mechanism through activation of soluble guanylate cyclase. Similar NO-dependent but not methylen blue insensitive response have been reported by Kitamura et al. (1993). The same effect of methylen blue has been reported to activate the particulate guanylate cyclase, an effect which was not inhibited by methylen blue, as well was soluble guanylate cyclase in various preparations (Waldman \& Murad, 1987 ; Horio \& Murad,1991). Kitamura et al. (1993) observed that the hyperpolarization induced by S-nitrosocysteine and sodium nitroprusside was not attenuated by methylen blue. Therefore, difference of potency of the eugenol-induced vasorelaxation, observed in the histamine-, noradrenaline- and $90 \mathrm{mM}\left[\mathrm{K}^{+}\right]_{0}$-induced contractions, might be caused by abilities of these stimulants on the release of vasoactive substances, but not by eugenol.

In the previous paper, we found that eugenol inhibited the $90 \mathrm{mM}\left[\mathrm{K}^{+}\right]_{0}$-induced contraction in the rat thoracic aorta without proportional reduction in the $\left[\mathrm{Ca}^{2+}\right]_{\mathrm{i}}$ (Nishijima et al., 1998). Eugenol has also been reported to inhibit the cellular respiration and to reduce the intracellular ATP concentration and pH (Jeng et al., 1994; Thompson et al., 1998). As similar responses could be observed in the actions of several metabolic inhibitors, such as cyanide, carbonyl cyanide and hypoxia (Kaira et al., 1989 ; Wray, 1990 ; Hasham et al., 1994 ; Aalkjaer et al., 1995; Taggart et al., 1997), Nishijima et al. (1998) concluded that actions of eugenol, resulting from its metabolic inhibition, probably attribute to its vasorelaxation. Regarding to the endothelium/adventitia-dependent relaxation by metabolic inhibition, Weir et al. (1991) reported that rotenone, an inhibitor of oxidative phosphorylation, inhibited the endotheliumdependent relaxation in rat and rabbit aorta. Therefore, it is possible that inhibition of EJP and release of vasoactive substances were caused by the metabolic inhibitor actions of eugenol. However, it is still uncertain whether metabolic inhibition would account for all responses induced by eugenol, including releases of substance P and CGRP from the peripheral nerve endings and spinal cord and activation of non-selective cation channels in the dorsal root ganglion cells (Bevan et al., 1990 ; Shibata et al., 1994 ; Ohkubo et al., 1997b).

\section{Acknowledgment}

The authors thank to Dr. K. Tsuruda for his technical assistance.

\section{References}

Aalkjaer, C. and Lombard, J.H. (1995) Effects of hypoxia on force, intracellular $\mathrm{pH}$ and $\mathrm{Ca}^{2+}$ 
concentration in rat cerebral and mesenteric small arteries. J. Physiol. (Lond.) 482 : 409-419.

Bevan, S. and Szolcsányi, J. (1990) Sensory neuron-specific actions of capsaicin: mechanisms and application. Trends Pharmacol. Sci. 11: 330-333

Brodin, P. and Rфed, A. (1984) Effects of eugenol on rat phrenic nerve and phrenic nerve-diaphragm preparations. Arch. Oral. Biol. 29 : 611-615.

Dohi, T., Anamura, S., Shirakawa, M., Okamoto, H. and Tshujimoto, A. (1991) Inhibition of lipoxygenase by phenolic compounds. Jpn. J. Pharmacol. 55 : 547-550.

Feng, J. and Lipton, J.M. (1987) Eugenol: antipyretic activity in rabbits. Neuropharmacology 26 : 1775-1778.

Hasham, M.I., Naumann, D., Kim, S.U., Cashman, N.R., Quamme, G.A. and Krieger, C. (1994) Intracellular calcium concentrations during metabolic inhibition in the motoneuron cell line NSC-19. Can. J. Physiol. Pharmacol. 72: 728-737.

Horio, Y. and Murad, F. (1991) Purification of guanylate cyclase from rod outer segments. Biochem. Biophys. Acta 1133 : 81-88.

Hume, W., Veaco, N. and Becker, R. (1982) Concentration-dependent depression of cellular respiration by eugenol. J. Dent. Res. 61: 202.

Hume, W.R. (1983) Effect of eugenol on constrictor responses in blood vessels of the rabbit ear. J. Dent. Res. 62 : 1013-1015.

Jeng, J.H., Hahn, L.J., Lu, F.J., Wang,Y.J. and Kuo, M.Y. (1994) Eugenol triggers different pathobiological effects on human oral mucosal fibroblasts. J. Dent. Res. 73 : 1050-1055.

Kaira, K., Mattsson, K. and Voipio, J. (1989) Fall in intracellular pH and increase in resting tension induced by mitochondrial uncoupling agent in cray fish muscle. J. Physiol. (Lond.) 408 : 271293.

Kitamura, K., Lian, Q., Andreas, C. and Kuriyama, H. (1993) S-nitrosocysteine, but not sodium nitroprusside, produces apamin-sensitive hyperpolarization in rat gastric function. $B r . J$. Phamacol. 109 : 415-423

Kuriyama, H., Kitamura, K. and Nabata, H. (1995) Pharmacological and physiological significance of ion channels and factors that modulate them in vascular tissues. Pharmacol. Rev. 47 : $387-573$.

Miranda, F.J., Torregrosa, G., Salom, J.B., Alabadi, J.A., Alvarez, C. and Alborch, E. (1992) Direct and neuromodulatory effects of histamine on isolated goat cerebral arteries. J. Autonom. Pharmacol. 12 : 25-36.

Nishijima, H., Uchida, R., Kameyama, K., Kawakami, N., Ohkubo, T. and Kitamura, K. (1998) Mechanisms mediating the vasorelaxing action of eugenol, a pungent oil, on rabbit arterial tissue. Jpn. J. Pharmacol. (in press)

Ohkubo, T. and Shibata, M. (1997a). The selective capsaicin antagonist capsazepine abolishes the antinociceptive action of eugenol and guaiacol. J. Dent. Res. 76: 848-851.

Ohkubo, T. and Kitamura, K. (1997b) Eugenol activates $\mathrm{Ca}^{2+}$-permeable currents in rat dorsal root ganglion cells. J. Dent. Res. 76: 1737-1744.

Patacchini, R., Maggi, C.A. and Meli, A. (1990) Capsaicin-like activity of some natural pungent substances on peripheral endings of visceral primary afferents. Naunyn-Schmiedeberg's Arch. Pharmacol. 342: 72-77.

Shibata, M., Ohkubo, T., Tsuruda, K. and Takahashi, H. (1994) Mode of analgesic action of phenolic dental medicaments through substance P release. Jpn. J. Oral. Biol. 36: 49-59 (Abstract in English).

Taggart, MJ., Menice, C.B., Morgan, K.G. and Wray, S. (1997) Effect of metabolic inhibition on intracellular $\mathrm{Ca}^{2+}$, phosphorylation of myosin regulatory light chain and force in rat smooth muscle. J. Physiol. (Lond) 499: 485-496.

Thompson, D.C., Barhoumi, R. and Burghardt, R.C. (1998) Comparative toxity of eugenol and its 
quinon methide metabolite in cultured liver cells using kinetic fluorescence bioassays. Toxicol. Appl. Pharmacol. 149 : 55-63.

Thompson, D. and Eling, T. (1989) Mechanism of inhibition of prostaglandin H synthase by eugenol and other phenolic peroxidase substrates. Lhol. Pharmacol. 36 : 809-817.

Waldman, S.A. and Murad, F. (1987) Cyclic GMP synthesis and function. Phamacol. Rev. 39 : 163196.

Weir, C.J., Gibson, I.F. and Martin, W. (1991) Effects of metabolic inhibitors on endotheliumdependent and endothelium-independent vasodilation of rat and rabbit aorta. Br. J. Pharmacol. 102 : 162-166.

Wray, S. (1990) The effects of metabolic inhibition on uterine metabolism and intracellular $\mathrm{pH}$ in the rat. J. Physiol. (Lond.) $423:$ 411-423.

(Received October 16, 1998: Accepted November 2nd, 1998) 